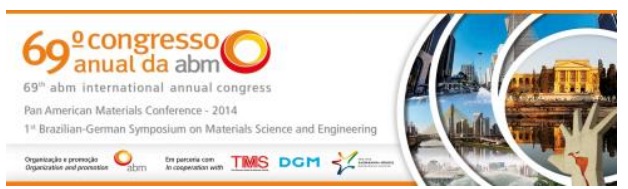

Tema: Forjamento

\title{
ESTUDO DEMOSTRATIVO DA IMPORTANCIA DOS SISTEMAS CAE/CAD/CAM NA FABRICAÇÃO DE MATRIZES PARA O FORJAMENTO: FORJAMENTO A QUENTE DE UM FLANGE DE MÉDIA COMPLEXIDADE*
}

\section{Resumo}

Ângela Selau Marques ${ }^{1}$ Carlos Alexandre Wurze ${ }^{2}$ Luana De Lucca de Costa ${ }^{3}$ Lírio Schaeffer ${ }^{4}$

A fabricação de matrizes para forjamento a quente vem sendo estudada com maior atenção nos últimos anos devido à necessidade de fabricação das ferramentas com maior rapidez e menor custo, estudo do processo de usinagem, com melhores propriedades mecânicas a fim de aumentar sua vida útil. Para atender as atuais necessidades do mercado são utilizados softwares de CAD e CAM e principalmente de máquinas CNC, que além da rapidez garantem a qualidade da usinagem das matrizes. O objetivo deste artigo é demonstrar, através de um estudo de caso, as etapas para a fabricação das matrizes superior e inferior, para forjamento a quente. Foram utilizados sistemas de CAD e CAM, o SolidWorks para modelagem da peça e das cavidades da ferramenta, e o software Edgecam para a programação e simulação da usinagem. As facilidades obtidas com a integração entre os sistemas CAD/CAM e máquina CNC conferem a manufatura de ferramentas muitos benefícios, dentre eles destaca-se a rapidez com a qual se pode fabricar uma matriz.

Palavras-chave: Usinagem; Softwares; Matrizes; Forjamento.

\section{STUDY OF THE IMPORTANCE OF SYSTEMS CAE/CAD/CAM IN THE MANUFACTURE OF DIES FOR FORGING: HOT FORGING OF A MIDDLE COMPLEXITY FLANGE}

\section{Abstract}

The manufacture of dies for hot forging has been studied with greater attention in recent years due to the need to manufacture tools with greater speed and lower cost, the study of the machining process, with improved mechanical properties in order to increase their shelf life. To meet current market needs of CAD and CAM software and CNC machines mainly, that in addition to quickly ensure the quality of machining of dies are used. The purpose of this article is to demonstrate, through a case study, the steps for making the upper and lower dies for hot forging. CAD and CAM systems were used SolidWorks to model the number of cavities and the tool, and Edgecam software for programming and simulation of machining. The facilities obtained by integration between CAD/CAM systems and CNC machine tools manufacturing confer many benefits, among them stands the speed with which it can manufacture an array.

Keywords: Machining; Software; Dies; Forging.

1 Tecnóloga em Fabricação Mecânica. Mestre em Engenharia pelo Programa de Pós-Graduação em Engenharia de Minas, Metalúrgica e Materiais (PPGEM). Laboratório de Transformação Mecânica. (LdTM), Depto. de Metalurgia, UFRGS, Porto Alegre, RS, Brasil; angela_selau@ufrgs.br.

2 Professor do Instituto Federal Sul Rio-Grandense (IFSul), Campus Sapucaia do Sul, Mestrando do Programa PPGEM, LdTM, Depto. de Metalurgia, UFRGS, Porto Alegre, RS, Brasil; cawurzel@sapucaia.ifsul.edu.br.

3 Engenheira Mecânica, Mestranda do PPGEM, LdTM, Departamento de Metalurgia, UFRGS, Porto Alegre, RS, Brasil; luana.lucca@ufrgs.br.

4 Engenheiro Mecânico, Prof. Dr.-Ing., Coordenador do Laboratório de Transformação Mecânica (LdTM), Depto. de Metalurgia, PPGEM, UFRGS, Porto Alegre, RS, Brasil; schaefer@ufrgs.br.

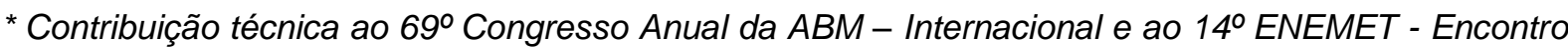
Nacional de Estudantes de Engenharia Metalúrgica, de Materiais e de Minas, 21 a 25 de julho de 2014, São Paulo, SP, Brasil.
} 


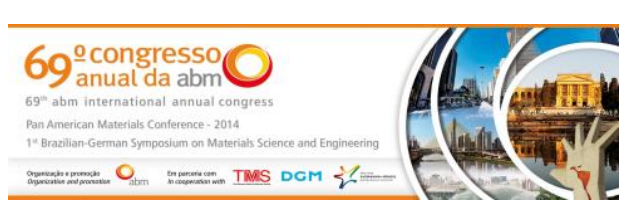

\section{INTRODUÇÃO}

A durabilidade de uma ferramenta é influenciada por uma série de fatores, tais como: velocidade de deformação e temperatura da peça forjada, o atrito entre a ferramenta e o material, a geometria da ferramenta, entre outros. Para que se tenha um produto economicamente viável e de boa qualidade é necessário uma boa interrelação entre todos estes fatores [1]. Ao desenvolver o projeto de uma ferramenta procura-se maximizar a vida útil da mesma. Viecelli [2] nos traz alguns itens, apresentados na Figura 1 que podem afetar a durabilidade de uma ferramenta:

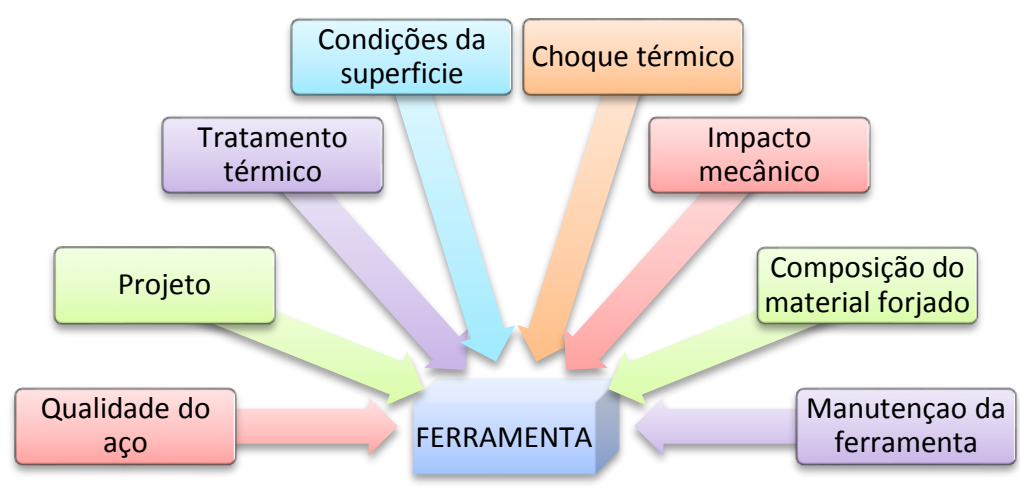

Figura 1. Parâmetros que afetam a vida de uma ferramenta [2].

O projetista define a cavidade da matriz baseado no modelo CAD projetado pelo designer, os softwares utilizados possuem recursos para desenvolver a matriz de forma rápida, mesmo em casos de peças com geometria complexa. O projeto final da matriz é transferido para a engenharia de processo a qual fica encarregada da fabricação da matriz. A grande vantagem trazida pelos softwares é que todo este processo é feito de forma integrada [3]. O modelo CAD é aberto em um software de CAM e este gera estratégias de usinagem, as quais serão responsáveis pela remoção do material até chegar à forma final da matriz. A utilização destas tecnologias é crucial para o desenvolvimento de uma matriz que atenda aos requisitos de qualidade e de um processo economicamente viável [4]. A Figura 2 mostra exemplos de ferramentas de peças com geometrias complexas.
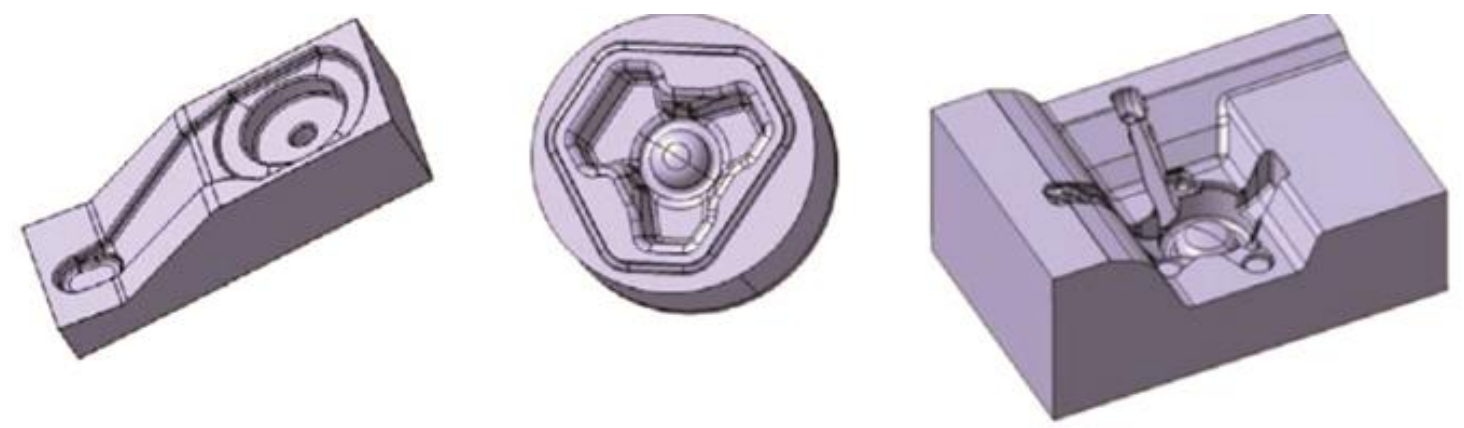

Figura 2. Exemplos de matriz de forjamento modelada em software CAD [4].

\subsection{Materiais Empregados em Matriz de Forjamento}

Os materiais utilizados na fabricação de matrizes para forjamento devem possuir elevada resistência ao desgaste e às solicitações de compressão. As matrizes que

* Contribuição técnica ao $69^{\circ}$ Congresso Anual da ABM - Internacional e ao 14ํㅡㄹ ENEMET - Encontro Nacional de Estudantes de Engenharia Metalúrgica, de Materiais e de Minas, 21 a 25 de julho de 2014, São Paulo, SP, Brasil. 
trabalham a quente devem ser considerados os aspectos relacionados com a manutenção das propriedades mecânicas do material. Os materiais mais utilizados, na fabricação de matrizes para forjamento, são os aços que contém como principais elementos de liga o Cromo, Tungstênio, Molibdênio e o Vanádio [5]

Embora exista uma grande quantidade de aços ferramentas, normalizados internacionalmente e desenvolvidos com a finalidade de suprir as mais diversas aplicações e solicitações, a indústria de ferramentaria utiliza uma quantidade reduzida de tipos de aços, os quais apresentam propriedades e desempenho consagrados ao longo do tempo, como por exemplo, AISI H13. [6]

$\mathrm{O}$ aço $\mathrm{H} 13$ é um aço ferramenta para trabalho a quente com uma excelente combinação entre dureza e resistência à fratura, com a manutenção destas propriedades em temperaturas elevadas, resistência a choques térmicos e às trincas por fadiga térmica, características importantes para ferramentas de forjamento. A Tabela 1 apresenta a composição química básica para o aço ferramenta AISI H13:

Tabela 1. Composição química do aço H13 [7]

\begin{tabular}{|l|l|l|l|l|l|l|}
\hline Elemento & $\mathrm{C}$ & $\mathrm{Cr}$ & $\mathrm{Si}$ & Mo & Mn & V \\
\hline \% peso & $0,32-0,45$ & $4,75-5,5$ & $0,8-1,2$ & $1,1-1,75$ & $0,2-0,5$ & $0,8-1,2$ \\
\hline
\end{tabular}

A boa estabilidade na dureza a quente deste aço se deve a presença de vanádio e tungstênio. Comparativamente com outras classes de aço, é percebida uma superioridade dos aços da classe $\mathrm{H}$ na resistência ao amolecimento em função do aumento da temperatura, devido ao endurecimento secundário que os aços com esta característica apresentam [8].

\subsection{Tratamento térmico do aço}

O ciclo de aquecimento e resfriamento a que são submetidos os materiais sob condições controladas de tempo, temperatura, atmosfera e velocidade de resfriamento, com os objetivos de alterar as suas propriedades ou conferir-lhes características determinadas, caracteriza o tratamento térmico dos metais, no caso deste artigo da liga de aço AISI H13 [2].

\subsubsection{Têmpera}

A têmpera consiste em resfriar o aço, após austenitização, a uma velocidade suficientemente rápida para evitar as transformações perlíticas e bainíticas a fim de obter-se a estrutura metaestável da martensita que é a mais dura que pode ser obtido nos aços ao carbono. O resfriamento rápido é quase sempre mandatório para se alcançar a máxima dureza, porém, um choque térmico severo pode causar distorção excessiva ou até mesmo fissuração, os elementos de liga, tornam a taxa de resfriamento menos acentuada, fato que comprova a utilização de aços ligados, principalmente, Cromo e Vanádio [9].

Para a têmpera do aço $\mathrm{H} 13$ o aquecimento deve ser entre 1010 e $1030^{\circ} \mathrm{C}$, temperatura de austenitização, já o resfriamento e o meio de tempêra dependem da microestrutura "alvo" e das propriedades mecânicas que se deseja obter.(Villares Metals)

\footnotetext{
* Contribuição técnica ao $69^{\circ}$ Congresso Anual da ABM - Internacional e ao 14ํㅡㄹ ENEMET - Encontro Nacional de Estudantes de Engenharia Metalúrgica, de Materiais e de Minas, 21 a 25 de julho de 2014, São Paulo, SP, Brasil.
} 


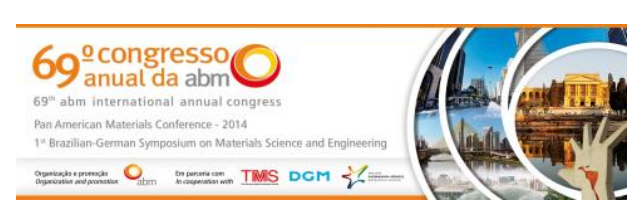

\subsubsection{Revenimento}

A martensita como temperada é extremamente dura e frágil. Peças nesta condição de alto tencionamento interno correm grande risco de trincar. A baixa tenacidade torna estas estruturas sem emprego prático, assim, todos os aços temperados devem passar pelo tratamento térmico subcritoco, conhecido como revenido ou revenimento. Este tratamento consiste em aquecer uniformemente até uma temperatura abaixo daquela de austenitização, mantendo o aço nesta temperatura por tempo suficiente para equalização de temperatura e obtenção das propriedades desejadas [9].

\subsection{Canal e Cavidade de Rebarba}

$\mathrm{Na}$ etapa final do forjamento, ao iniciar-se a formação da rebarba, em virtude da presença do estrangulamento ou "garganta da rebarba" entre as duas matrizes, as tensões compressivas na cavidade das matrizes elevam-se consideravelmente para que haja o preenchimento de todas as partes dessa cavidade.

Ao iniciar a formação da rebarba a força aumenta rapidamente, até que a cavidade seja completamente preenchida. É nesta fase do processo que os detalhes de maior complexidade da matriz definem a força do forjamento e também onde a pressão no interior da matriz garante o forjamento completo da peça. No caso do forjamento a quente, o resfriamento que ocorre no material, presente no canal de rebarba, faz com que o declive da curva seja mais acentuado nesta região (Figura 3) [5].

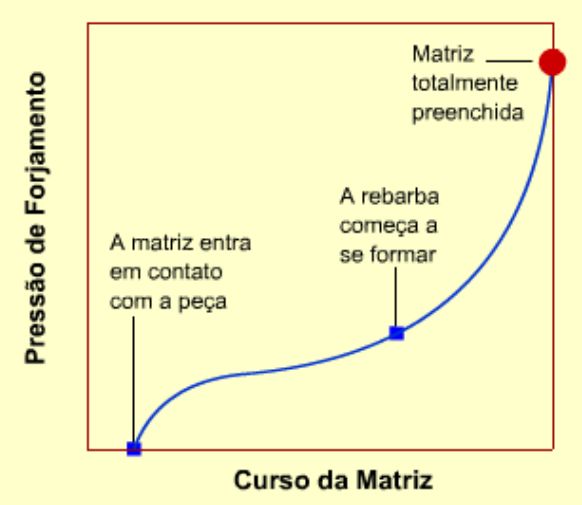

Figura 3. Curva típica de pressão de forjamento [10].

O escoamento do material através do canal de rebarba deverá ser mais difícil do que o preenchimento dos detalhes internos da matriz. Além disso, o volume de material no interior da matriz deve ser suficiente para assegurar o seu preenchimento.

A Figura 4 apresenta quatro tipos de canais de rebarbas e a Tabela 2 mostra as recomendações sobre as dimensões.

\footnotetext{
* Contribuição técnica ao $69^{\circ}$ Congresso Anual da ABM - Internacional e ao 14ํㅡㄹ ENEMET - Encontro Nacional de Estudantes de Engenharia Metalúrgica, de Materiais e de Minas, 21 a 25 de julho de 2014, São Paulo, SP, Brasil.
} 


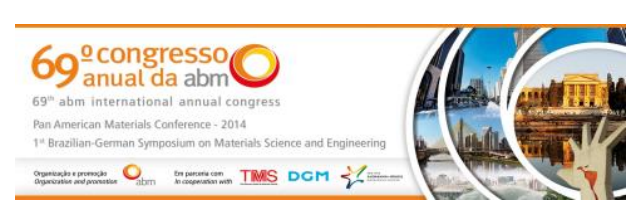

tempo de usinagem das peças forjadas. Batalha [11] recomenda a utilização de ângulos de até $7^{\circ}$ graus para o forjamento de alumínio.

\section{RESULTADOS E DISCUSSÕES}

Os softwares de CAE/CAD/CAM fornecem um meio para estudar em detalhes problemas complexos que conduzem a uma melhor compreensão e, na maioria das vezes, à otimização do processo [3]. Estes sistemas podem ser aplicados de diversas maneiras, permitindo identificar problemas e encontrar soluções ainda na etapa de desenvolvimento.

Para o desenvolvimento do projeto e a fabricação da matriz de forjamento deste estudo foram utilizados três softwares diferentes:

1. SolidWorks para modelagem da peça e das matrizes;

2. Simufact Forming para simulação do processo de forjamento;

3. Edgecam para programação da usinagem

A primeira etapa é a modelagem geométrica da peça a ser forjada. A Figura 6 mostra a representação gráfica em $3 D$ da peça, a modelagem da peça foi desenvolvida no software SolidWorks. A utilização deste sistema permite uma série de automatizações com relação à modelagem da peça, da geratriz e das matrizes. Pois, a partir do momento que a peça está modelada no SolidWorks pode-se desenvolver todo ferramental de forma automática. Todavia, a característica deste sistema que mais contribui nesta pesquisa é a possibilidade de alterar facilmente qualquer medida da peça, sendo que estas alterações se regeneram de forma automática de acordo com as novas dimensões atribuídas.
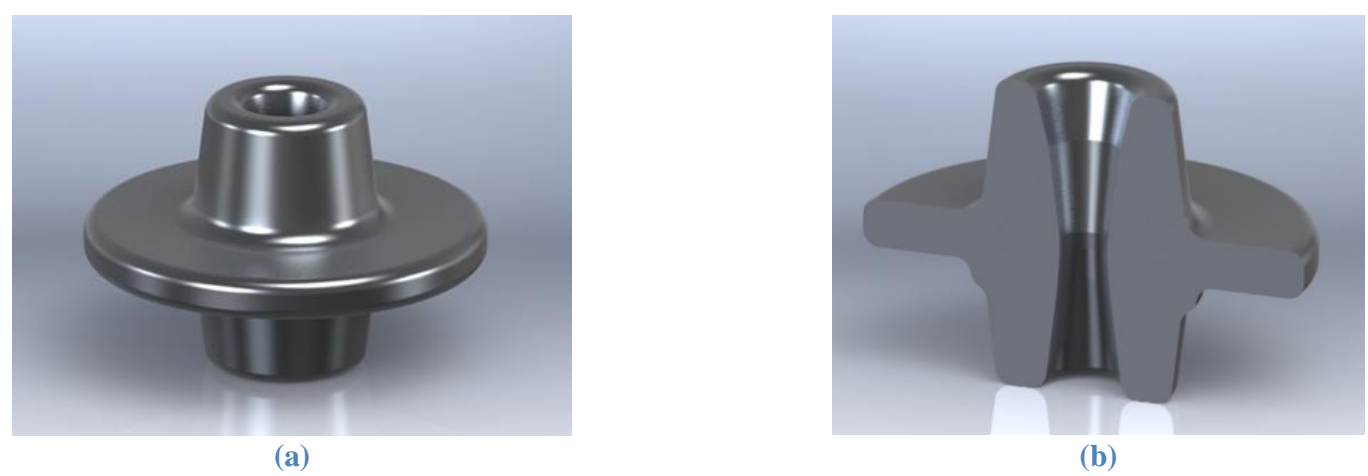

Figura 1. (a) Representação 3D da peça a ser forjada (b) Vista em corte da peça.

Para uma representação virtual da peça forjada projetou-se uma aproximação do que poderia ficar de rebarba na peça, desta forma foi possível estimar, pela lei da conservação do volume as dimensões da geratriz inicial. O desenho do canal e do poço de rebarba é necessário também para que se possa desenvolver o projeto do ferramental adequadamente.

Com o projeto da matriz pronto, inicia-se a simulação do processo de forjamento com o software Simufact Forming. Esta etapa é de suma importância, pois com a simulação pode-se avaliar os parâmetros envolvidos no processo, tais como: geometria do billet, geometria da matriz e dos canais de rebarba, força de forjamento, temperatura, atrito, entre outros. Através dos resultados apresentados pela simulação pode-se verificar se a peça forjada será obtida livre de defeitos. 0 método de "elemento finito" foi o escolhido para analisar o processo de forjamento e devido à simetria da peça, utilizou-se a simulação em 2D, cujos resultados são mais

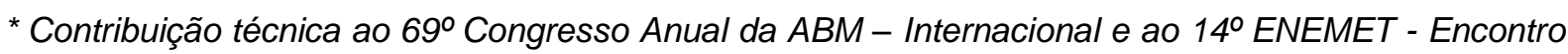
Nacional de Estudantes de Engenharia Metalúrgica, de Materiais e de Minas, 21 a 25 de julho de 2014, São Paulo, SP, Brasil.
} 


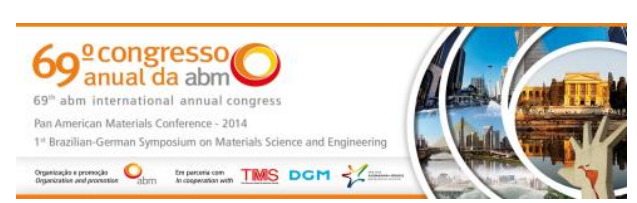

rápidos de serem calculados. Esta simplificação torna a simulação menos complexa sem comprometer a qualidade dos resultados, conforme indica a literatura apresentada pelo fabricante do software e artigos [12,13].

Através da simulação observou-se que seria necessária uma força elevada para o forjamento da peça, em função disto, modificou-se o canal de rebarba, o qual facilitou o escoamento do material, sem comprometer o preenchimento da peça, conforme pode ser observado na Figura 7.

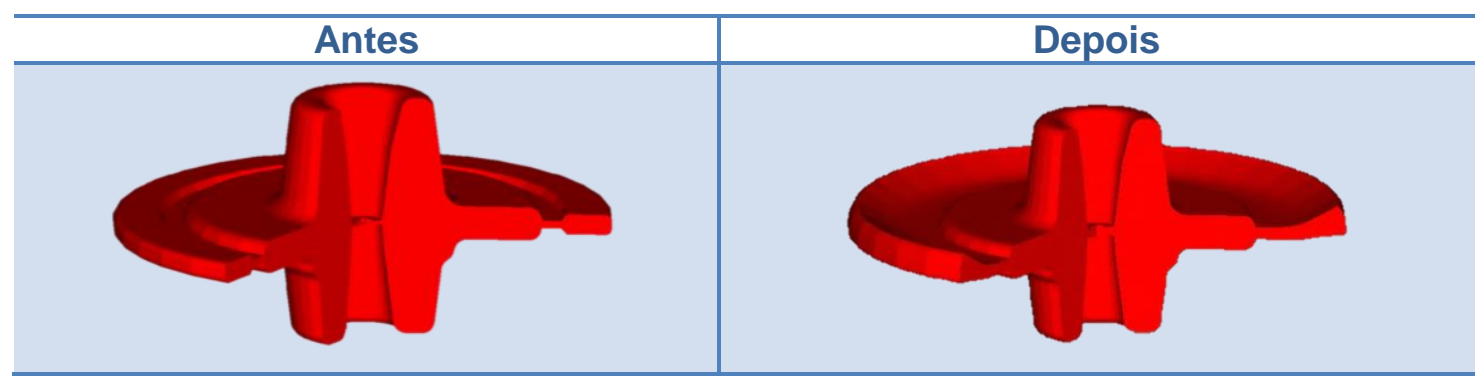

Figura 7. Canais de rebarba estudados na simulação

Vários parâmetros podem observados através da simulação do processo de forjamento. Dentre eles, destacam-se os seguintes, conforme Figura 8:
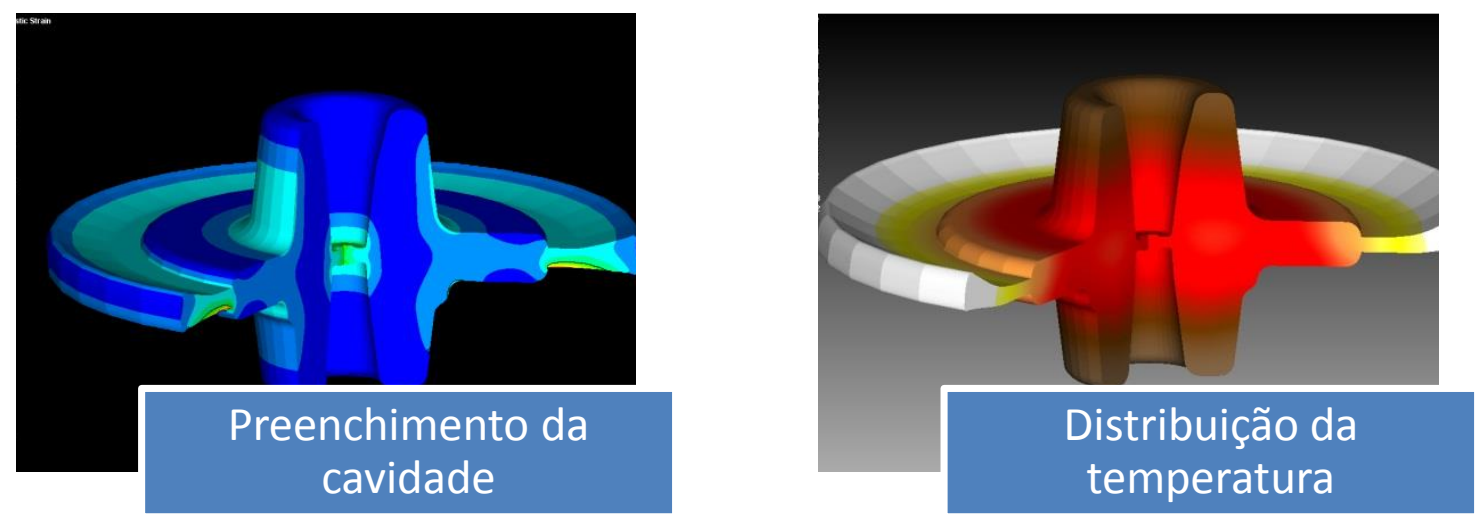

Figura 8. Simulação do forjamento

\subsection{Fabricação das Matrizes}

O material utilizado na fabricação de matrizes para forjamento a quente deve suportar temperaturas elevadas. Os aços da classe $\mathrm{H}$, ao Cromo, são os que satisfazem, com maior êxito, as solicitações previstas no forjamento deste estudo. Com base nisso, o aço selecionado para a fabricação desta matriz foi o H13, cuja composição química esta exposta na Tabela 1 anteriormente.

As matrizes são constituídas de duas metades: a matriz superior e a matriz inferior conforme Figura 9.

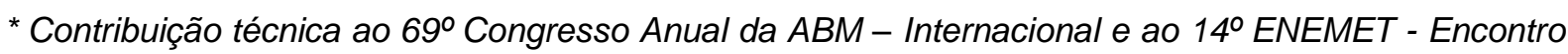
Nacional de Estudantes de Engenharia Metalúrgica, de Materiais e de Minas, 21 a 25 de julho de 2014, São Paulo, SP, Brasil.
} 


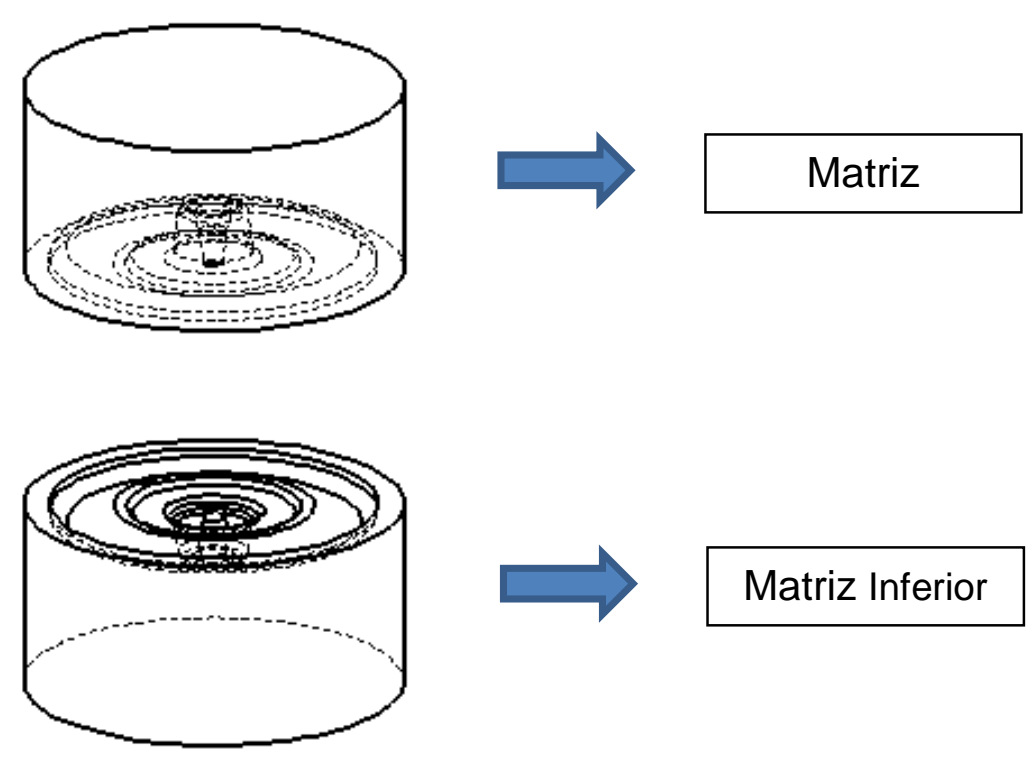

Figura 9. Vista da matriz superior e inferior.

A primeira etapa de usinagem do ferramental foi o corte na serra para divisão do tarugo em duas partes, que servirá de base para a matriz inferior e a superior. Por ser uma serra de uso educacional, a mesma estava com a serra-fita gasta para efetuar o corte, o que ocasionou um problema conhecido popularmente na indústria por "corte salame". Em função disso, foi necessária uma operação de usinagem no torno paralelo universal para facear as duas peças e, por fim, utilizou-se a retifica para fornecer o acabamento dimensional desejado garantindo precisão nas faces dos blocos que serão usinados em um centro de usinagem CNC. A figura 10 mostra os blocos, após a retificação, prontos para serem utilizados na fabricação da matriz inferior e superior.

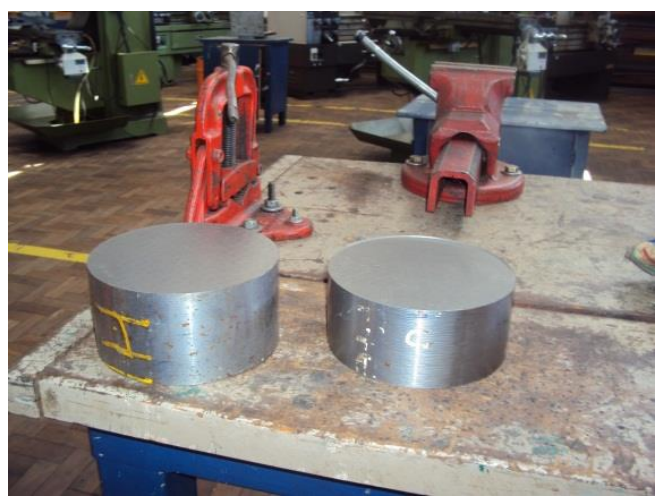

Figura 10. Blocos de H13 prontos para serem usinado.

Os modelos CAD, desenvolvidos no SolidWorks, foram importados em um software de CAM, chamado de Edgecam. Através deste sistema é possível gerar estratégias e simular a usinagem para que se possa verificar o resultado final, e se necessário, fazer correções antes da fabricação física do modelo.

A Figura 11Erro! Fonte de referência não encontrada. mostra a matriz no software Edgecam, com as respectivas linhas de usinagem que representam o caminho percorrido pela ferramenta que fará a remoção do material:

* Contribuição técnica ao 69 Congresso Anual da ABM - Internacional e ao 14ํㅡㄹ ENEMET - Encontro Nacional de Estudantes de Engenharia Metalúrgica, de Materiais e de Minas, 21 a 25 de julho de 2014, São Paulo, SP, Brasil. 

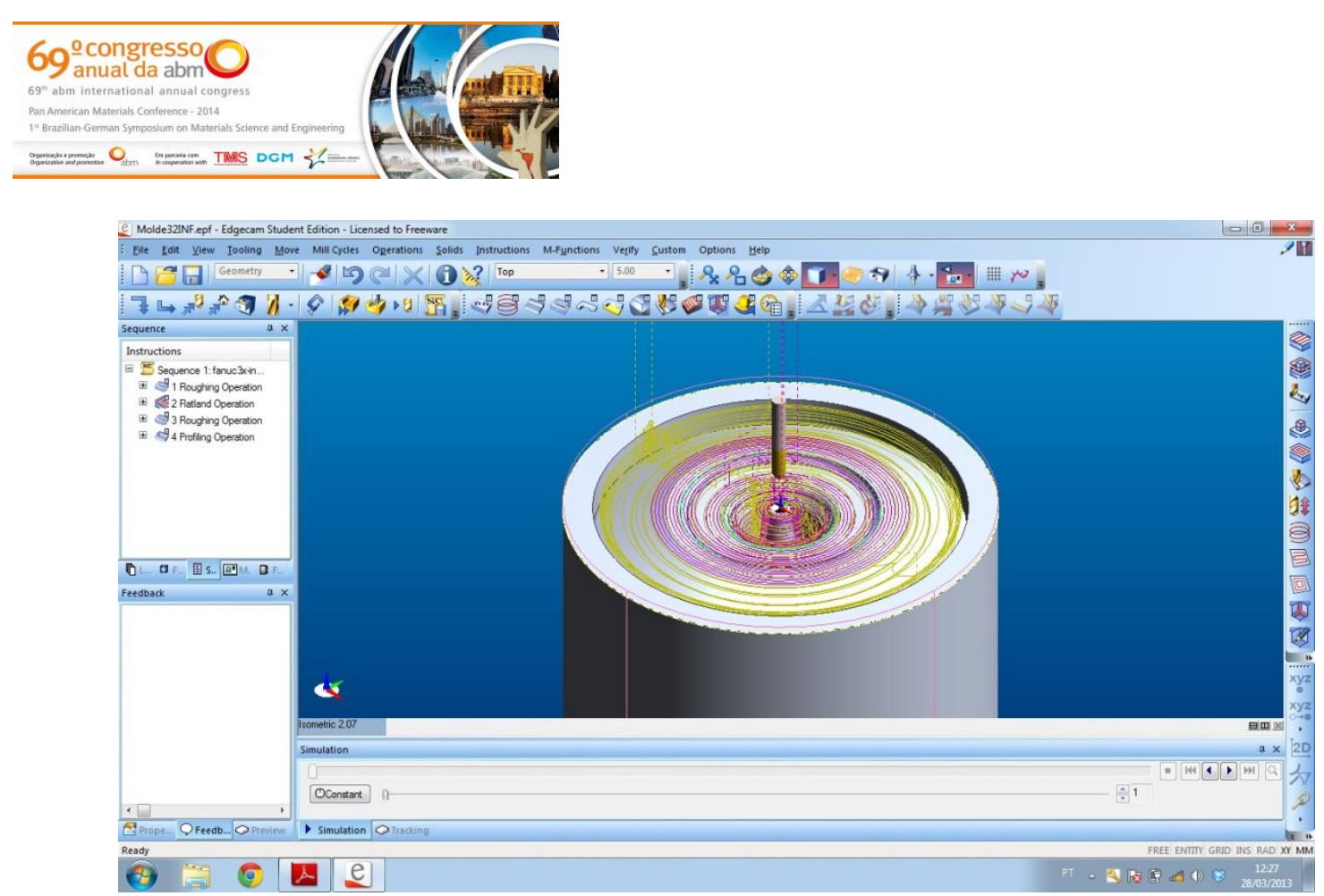

Figura 11. Geração do programa de usinagem no software Edgecam

Depois de finalizado o programa no software Edgecam os dados são enviados ao Centro de Usinagem para a fabricação das cavidades das matrizes inferior e superior. A máquina utilizada para isso foi um centro de usinagem vertical da Romi, modelo Discovery 760, com comando Siemens 810D. O CNC é conectado a um computador externo através de uma interface padrão chamada de RS-232. Através desta interface o computador transfere os dados gerados pelo CAM para a máquina CNC, conforme ilustrado na Figura 12.

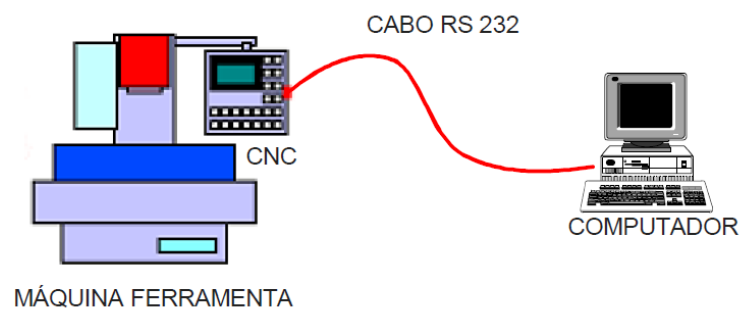

Figura 12. Transmissão de dados do computador para o CNC [14].

Foram utilizadas 5 ferramentas na fabricação das matrizes, primeiro uma TOPO de $10 \mathrm{~mm}$ de diâmetro para o desbaste inicial, depois uma esférica de $6 \mathrm{~mm}$ para um redesbaste e para as estratégias de acabamento dos perfis uma esférica de $4 \mathrm{~mm} e$ uma de $2 \mathrm{~mm}$ de diâmetro. Inicialmente usinou-se a matriz inferior, e durante 0 redesbaste ocorreu a quebra de uma ferramenta, a esférica de $6 \mathrm{~mm}$, em função disso, alterou-se 2 parâmetros de usinagem, são eles: diminuição da velocidade de avanço e do incremento lateral da ferramenta. Depois destas modificações não ocorreu mais nenhuma quebra de ferramenta.

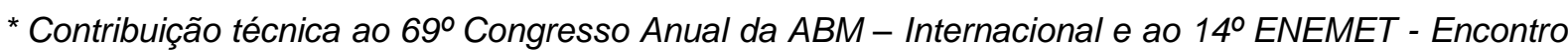
Nacional de Estudantes de Engenharia Metalúrgica, de Materiais e de Minas, 21 a 25 de julho de 2014, São Paulo, SP, Brasil.
} 

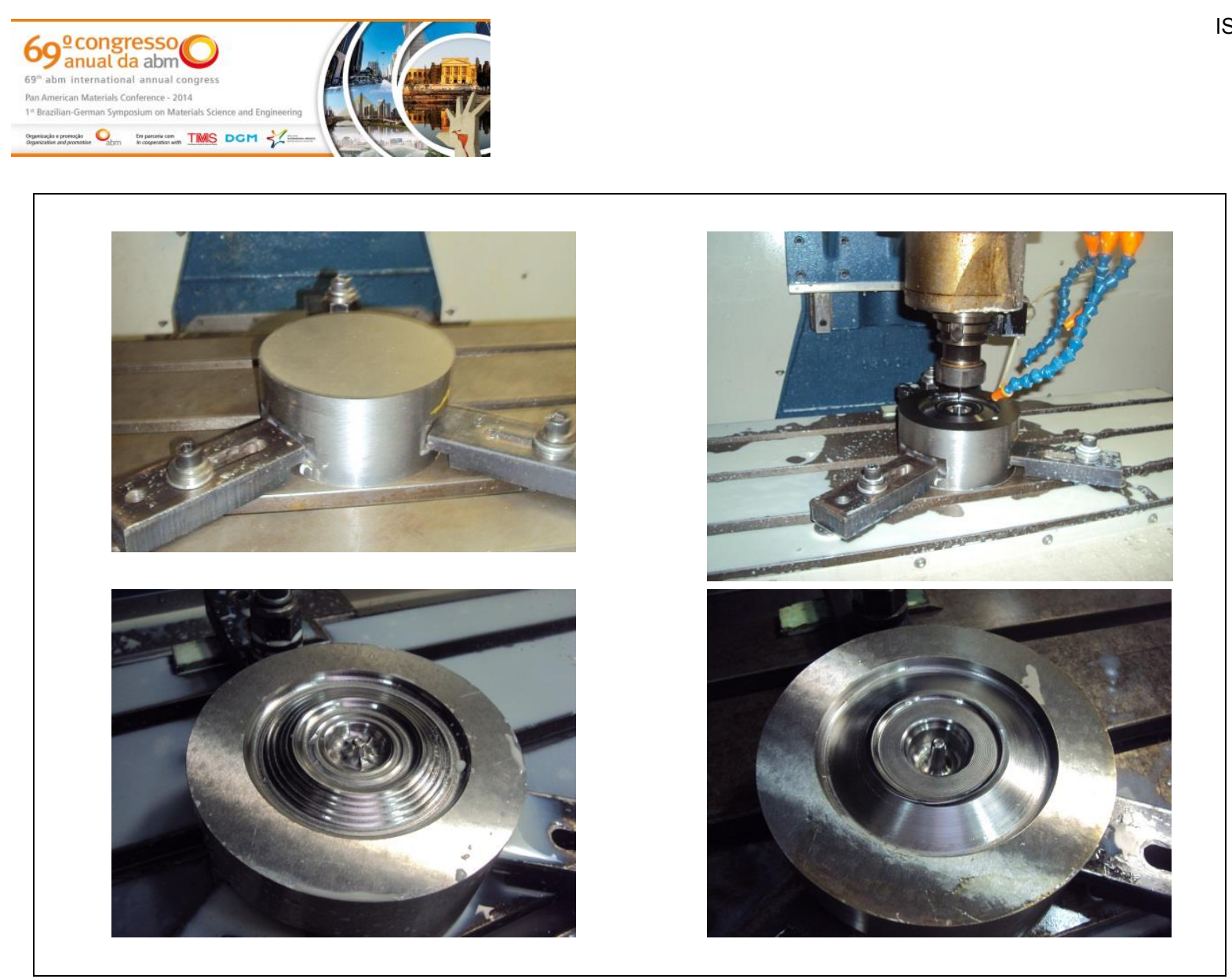

Figura 13. Sequência de fabricação das matrizes.

O ferramental possui dois pinos guias de $12 \mathrm{~mm}$ de diâmetro. É necessário colocalos para corrigir eventuais deslocamentos entre a matriz inferior e a superior devido a folgas existentes no equipamento. A fixação incorreta ou movimentação das matrizes durante a conformação também são problemas corrigidos pela utilização dos pinos guias. A folga entre o pino, fixado na ferramenta superior com seu alojamento na matriz inferior é de $0,1 \mathrm{~mm}$. Estes pinos iniciam o guiamento do ferramental $30 \mathrm{~mm}$ antes do fechamento das matrizes.

Por fim, realiza-se o polimento e o tratamento térmico das matrizes, apesar deste item não ser objeto de estudo no presente trabalho, deve-se salientar a sua importância para o processo de degradação de ferramentas, pois um tratamento inadequado é altamente influenciável para o processo de fadiga térmica e desgaste abrasivo de matrizes de conformação a quente.

\section{CONCLUSÃO}

O software Simufact mostrou, através da simulação do forjamento, que o canal de rebarba influencia diretamente na força e no comportamento do material durante 0 forjamento. Em função disso, optou-se por um canal de rebarba diferente do projetado incialmente. Desta forma facilitou-se a fabricação das matrizes e diminuise a força necessária para o forjamento. Outro fator importante influenciado pelo canal de rebarba é o desgaste da ferramenta, que diminui ao utilizar-se uma altura maior.

A fabricação destas matrizes, com a utilização do SolidWorks e Edgecam nos permite verificar a facilidade e agilidades que os sistemas CAD/CAM trazem para 0 processo de usinagem, principalmente quando utilizados de forma integrada. $O$ software Edgecam demonstra ser uma ótima ferramenta de trabalho para diversas aplicações voltadas a usinagem, tanto para fabricação de cavidades quanto de

\footnotetext{
* Contribuição técnica ao $69^{\circ}$ Congresso Anual da ABM - Internacional e ao 14ํㅡㄹ ENEMET - Encontro Nacional de Estudantes de Engenharia Metalúrgica, de Materiais e de Minas, 21 a 25 de julho de 2014, São Paulo, SP, Brasil.
} 


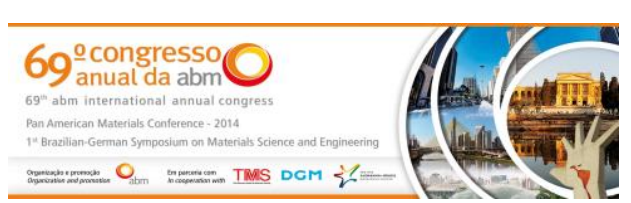

produtos. A complexidade dos perfis de usinagem é um fator decisivo para a escolha do CAM, pois o software também pode usinar matrizes de formas complexas, identificando colisões entre a ferramenta de usinagem e a matriz, ou até mesmo elementos de fixação. Outra vantagem importante na utilização de um sistema CAM é a otimização do processo de manufatura. Os softwares permitem obter um ganho significativo no tempo de programação, pois, através dele é possível testar e escolher estratégias de forma virtual sem a necessidade de testes físicos.

Não mencionar trabalhos não finalizados. Podem ser apresentadas novas hipóteses, quando bem justificadas e incluídas as recomendações, porém, estas precisam ser claras e fundamentadas nos objetos dos estudos realizados.

\section{Agradecimentos}

Os autores agradecem a Universidade Federal do Rio Grande do Sul (UFRGS), e as instituições de fomento à pesquisa CNPq e CAPES pelo apoio financeiro.

\section{REFERÊNCIAS}

1 Schaeffer L. Introdução ao projeto de ferramentas para forjamento a quente em matriz fechada. Ferramental, 2006: 19-28.

2 Viecelli A. Projeto de matrizes fechadas de forjamento a quante para peças axissimétricas com rebarba auxiliado pelo computador, 1995. Dissertação de Mestrado. Porto Alegre, RS: PPGEM/UFRGS.

3 Al-Omari F, Al-Jarrah M. Development of a CAD/CAM system for simulating closed forging process using finite element. Emerald, 2008: 302-312.

4 Mawussi KB, Tapie L. A knowledge base model for complex forging die machining. Computers \& Industrial Engineering, 2007, pp. 84-97.

5 Martins P, Rodrigues, J.Tecnologia Mecânica: Tecnologia Da Deformação Plástica, 2005; II. Lisboa: Escolar Editora.

6 Gabardo JF. Estudo da tenacidade do aço ferramenta H13, 2008, UFPR, Curitiba

7 Handbook AM. Properties and Selection Irons Steels and High, 2002 vol. 1.

8 Smith W. Structure and Properties of Engineering Alloys, 1993, New York: McGraw-Hill.

9 Silva ALVC, Mei PR. Aços e ligas especiais, 2010 São Paulo: Editora Blucher.

10 Dieter GE. Metalurgia Mecânica, 1981, Rio de Janeiro: Guanabara Dois.

11 Batalha FG. Introduçao a Manufatura Mecanica, 2003, São Paulo.

12 Buijk, A. Finite Volume (FV) and Finite Element (FE) integration in Simufact.forming. Simufact-Americas LLC, 2008.

13 Sedighi M, Tokmechi S. A new approach to preform design in forging process of complex parts. Journal of materials processing technology, 314-324.

14 Helleno AL. Fatores que influenciam a usinagem de moldes e matrizes com altas velocidades. Revista de Ciência \& Tecnoligia, 2004: 7-14

\footnotetext{
* Contribuição técnica ao $69^{\circ}$ Congresso Anual da ABM - Internacional e ao 14ํㅡㄹ ENEMET - Encontro Nacional de Estudantes de Engenharia Metalúrgica, de Materiais e de Minas, 21 a 25 de julho de 2014, São Paulo, SP, Brasil.
} 